\title{
Answer to the Letter to the Editor of L. Uhrenholt et al. concerning "Do X-ray-occult fractures play a role in chronic pain following a whiplash injury?" by Hertzum-Larsen R, Petersen H, Kasch H, Bendix T, Eur Spine J, 2014; DOI 10.1007/s00586-014-3362-3
}

\author{
R. Hertzum-Larsen · Henrik Petersen • \\ Helge Kasch • Tom Bendix
}

Received: 21 July 2014/Revised: 27 July 2014/Accepted: 28 July 2014/Published online: 15 August 2014

(c) Springer-Verlag Berlin Heidelberg 2014

We welcome the comments on the article "Do X-rayoccult fractures play a role in chronic pain following a whiplash injury?". Uhrenholt et al. pointed out that 9 of the 13 patients, who had an abnormal SPECT after 6-months of follow-up, had been SPECT-normal at baseline. They see this as evidence that many of the abnormal findings at baseline were false positives.

We agree that possible problems with diagnostic properties of SPECT mean that our title and conclusion was too strong: our study was not suited to examine X-ray occult fractures.

The title of the article as it was first submitted to the European Spine Journal was indeed "Do early bone SPECT scan predict chronic pain following a whiplash injury?", intending to make it a pragmatic, prognostic study of SPECT in whiplash-associated disorders (WAD), rather than a study of the causes of WAD, but this was changed as requested in the review process. It is our mistake that we agreed to this change.

We find that the value of this study lies in the finding that introducing the SPECT scan early after a whiplash injury is not suited for predicting chronicity, irrespective the SPECT findings are expressions of fractures, diagnostic errors or something else. The inception-cohort design of the study was well suited for this purpose because we had the opportunity to follow a cohort of whiplash-trauma victims regarding their natural history from the acute phase, to later stages of either resolution or chronicity.

We appreciate this opportunity to make the above clarification.

Conflict of interest None.
R. Hertzum-Larsen $(\bowtie) \cdot T$. Bendix

Back Research Unit, Center for Rheumatology and Spinal Diseases, Glostrup University Hospital, Nordre Ringvej 57, 2600 Glostrup, Denmark

e-mail: rasmushertzumlarsen@gmail.com

H. Petersen

Department of Nuclear Medicine, Odense University Hospital, Sdr. Boulevard 29, 5000 Odense, Denmark

H. Kasch

The Headache Clinic and Danish Pain Research Center, Aarhus

University Hospital, 8000 Aarhus, Denmark

T. Bendix

Department of Sports Medicine and Clinical Biomechanics,

University of Southern Denmark, 5230 Odense, Denmark 